NBER WORKTNG PAPER SERIES

\author{
DETERIORATION OF THE TERMS OF TRADE AND \\ CAPITAL ACCUMULATION: A REFXAMINATION OF \\ THE LAURSEN-METZLER EFFECT
}

\author{
Partha Sen \\ Stephen $J$. Turnovsky \\ Working Paper No. 2616 \\ NATIONAL BUREAU OF ECONOMIC RESEARCH \\ 1050 Massachusetts Avenue \\ Cambridge, MA 02138 \\ June 1988
}

This research is part of NBER's program in International studies. Any opinions expresssed are those of the authors and not those of the National Bureau of Economic Research. 
NBER Working Paper No. 2616

June 1988

\section{DETERIORATION OF THE TERMS OF TRADE AND \\ CAPITAL ACCUMULATION: A REEXAMINATION OF \\ THE LAURSEN-METZLER EFFECT}

\section{ABSTRACT}

This paper analyzes the effects of both a permanent and a temporary deterioration in the terms of trade on a small open economy. The model, based on intertemporal optimization, emphasizes the labor-leisure choice and the role of capital accumulation. There are two main conclusions to be drawn from the analysis. The first is that in all cases the transitional dynamics depends critically upon the long-run response of the capital stock to the deterioration in the terms of trade. This has been shown to consist of a substitution effect, which is negative, together with an income effect, which is positive. Secondly, since the steady state equilibrium depends upon the initial conditions of the economy, a temporary shock, by altering these initial conditions for some later date when the shock ceases, leads to permanent effect on the economy.

In the case where the substitution effect dominates, a deterioration in the terms of trade leads to a short-run reduction in investment and a short-run current account surplus, contrary to the Laursen-Metzler effect.

However, when the long-run income effect dominates, the deterioration in the terms of trade leads to a short-run investment boom, accompanied by a short-term current account deficit. The Laursen-Metzler effect prevails, although it is driven by investment, rather than by savings behavior.

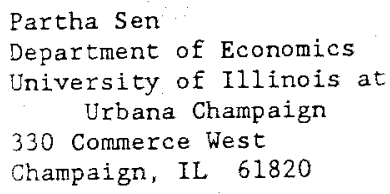

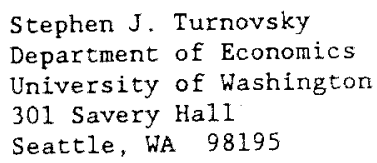




\section{INTRODUCTION}

The effect of a deterioration in the terms of trade faced by small open economy has been the subject of some controversy since the early 1950's when Laursen and Metzler (1950) and Harberger (1950) developed what has become known in the literature as the Laursen-Metzler effect. This predicted that a worsening of the terms of trade lowers real income, thereby lowering savings, and given investment, leading to a deterioration of the current account balance.

This proposition has recently been the subject of considerable scrutiny within a neoclassical framework. The focus has shifted away from the static Keynesian savings and investment functions, towards an analysis based on intertemporal optimization. The reappraisal was initiated by Obstfeld (1982) and has been further pursued within a variety of related frameworks by a number of authors, see e.g., Svensson and Razin (1983), Persson and Svensson (1985), Bean (1986).

One conclusion to emerge from this literature is that the validity or otherwise of the LaursenMetzler proposition depends critically upon the assumptions and specifications of the model. For example; Obstfeld (1982) showed how, if the rate of time preference depends positively upon utility, then a deterioration in the small country's terms of trade leads it to save more and to run a current account surplus, thereby contradicting the Laursen-Metzler proposition. On the other hand, one can show if the rate of time preference is taken to be constant, a permanent terms of trade shock causes the economy to jump immedately to its new steady state there is no effect on the current account. By contrast, temporary end anticipated fut ure terms of trade shocks still generate nondegenerate current account dynamics due to intertemporal consumption smoothing and price speculation: ${ }^{1}$

Using a two-period framework, Svensson and Razin (1983) demonstrate that a priori, the effects of a rise in the price of importables is ambiguous. Extending their model to an infinite horizon they show how if the discount rate is increasing in utility, then the Obstfeld (1982) results are confirmed.

More recently, Persson and Svensson (1985) have analyzed the effect of a terms of trade shock within an overlapping generations model. They demonstrate how the effect depends critically upon whether the shock is temporary or permanent on the one hand, and whether it is anticipated or unanticipated on the other. The response of the economy is very different, depending upon the 
duration of the shock and when the news of the shock is received.

The present paper analyzes the effects of a terms of trade shock within an infinite horizon utility maximizing framework. Two key features of the model stand out and should be stressed. First, we allow for the labor-leisure choice, thereby endogenizing employment, and incorporating an aspect which has been ignored by previous authors, with the exception of Bean (1986). Secondly, and equally importantiy, we allow for capital accumulation and derive a $q$-theoretic investment function as in Abel and Blanchard (1983) and Hayashi (1982). Our analysis therefore focuses on the dynamics of employment, capital accumulation, and output. These are obviously critical, but have received little attention from previous authors.

Three types of disturbances in the terms of trade are analyzed, namely an unanticipated permanent, an unanticipated temporary, and a future anticipated permanent shock. The main result to emerge is that in all cases, the short-run dynamics of the economy depends critically upon the long-run response of the capital stock to the deterioration in the terms of trade. This in turn is shown to consist of a negative substitution effect, together with a positive income effect. The resulting behavior depends upon which effect dominates and neither one possibility, nor the cther, can be ruled out a priori.

In the case which we suggest below to be more plausible-namely, where the substitution effect dominates-we show how irrespective of whether the terms of trade deterioration is permanent or temporary, anticipated or unanticipated, the current account goes into surplus when the news of the shock arrives. This is contrary to the Laursen-Metzler proposition and is the consequence of a fall in investment. By contrast, in the case where the income effect dominates, the news of such shocks generates an investment boom, driving the current account into deficit. While in this case the Laursen-Metzler effect on the current account is vind ic ated, the action is coming primarily from the investment side of the model rather than from savings as they originally argued.

Other authors have recently adopted variants of the $q$-theoretic investment function to analyze various macroeconomic disturbances in an intertemporal optimizing framework. Before proceeding, it is useful to note their contributions and to relate the present paper to this literature. For example, Brock (forthcoming) uses this type of approach to analyze alternative fiscal policies in a model which has both traded and nontraded goods, with the role of the latter being solely to install 
capital Also, Matsuyama (1987) introduces the Hayashi type cost of adjustment into a finite lifetime Blanchard (1985) model in order to analyze the macroeconomic effects of oil price shocks. In a subsequent paper Matsuyama (1988) he considers a terms of trade shock in an overlapping generations model using a Heckscher-Ohlin production specification.

The present model differs from these contributions in several key ways. First, of these three papers only Matsuyama (1988) deals with changes in the terms of trade, which are the focus of this paper. The Heckscher-Ohlin framework that it adopts emphasizes very different aspects and offers very different insights into the adjustments following a terms of trade shock. Specifically, it focuses on the role of sectoral capital intensity, while our model emphasizes the relative importance of the income and substitution effects resulting from the change. Most importantly, the existing literature focuses on inelastic labor, while our model endogenizes labor through the labor-leisure choice. Not only are the aggregate employment effects of terms of trade changes of interest per se, but the endogeneity of labor turns out to be crucial to the dynamics of the adjustment. For reasons which will be discussed below; without it the dynamics would degenerate; instead, the steady state adjustment would occur instantaneously.

The rest of the paper is organized as follows. Section 2 sets out the model ${ }_{x}$ and the following section analyzes is equilibrium dynamics. Section 4 examines the long-run effectg of a terms of trade shock, while Section 5 examines its short-run and dynamic effects. Conclusions are summarized in Section 6 .

\section{THE FRAMEWORK}

The economy produces and consumes a domestic good and in addition, imports another good from abroad. The relative price of the imported good is taken as given. The economy has access to the world capital market, where it can borrow or lend as much as it wants at a given interest rate, though subject to an intertemporal budget constraint. Domestic firms are assumed to be owned by domestic consumers.

The representative consumer's decisions are determined by solving the following intertemporal optimization problem: 


$$
\operatorname{Max} \int_{0}^{\infty} U[V(x, y), l] e^{-\delta t} d t
$$

subject to the flow budget constraint ${ }^{2}$

$$
p \dot{b}=w \ell+\pi+i{ }^{m} p b-x-p y
$$

and initial condition

$$
b(0)=b_{0}
$$

where

$I=$ consumption of the domestically produced good,

$y=$ consumption of the imported good,

$p=$ relative price of the imported good, taken to be parametrically given to the small open economy,

$\ell=$ labor supplied,

$b=$ real stock of foreign assets held by the household,

$w=$ real wage rate,

$\pi=$ real profits distributed to the household,

$\delta=$ consumer's discount rate,

$i^{*}=$ given world rate of interest.

The instantaneous utility function $U$ is assumed to be weakly separable in $V$ and $\ell_{i}$ i.e., in goods and leisure (which is $1-\ell$, where 1 is the total endowment of time). The function $U$ is increasing and strictly concave in goods and leisure, i.e.,

$$
U_{v}>0, \quad U_{\ell}<0 ; \quad U_{v v}<0, \quad U_{\ell \ell}<0, \quad U_{v v} U_{\ell \ell}-U_{v \ell}^{2}>0
$$

Similarly, $V$ is increasing and concave in the two goods

$$
V_{x}>0, V_{y}>0, V_{x x}<0, V_{y y}<0, V_{x x} V_{y y}-V_{x y}^{2}>0
$$

We also assume that the two goods are Edgeworth complementary, as are goods and leisure, i.e., 


$$
U_{x y} \equiv U_{u} V_{x y}+U_{u v} V_{x} V_{v}>0, U_{u \ell}<0
$$

In determining his optimal plans for $x, y, \ell$, and $b$, the representative consumer is assumed to take $p, \pi, w$ as given. These decisions are made subject to the budget constraint (1b), which is expressed in flow terms. This relationship is straightforward; the only point worth noting is that for simplicity, we abstract from all forms of taxation.

The current-value Hamiltonian for the housebold maximization problem is given by

$$
U(V(x, y), \ell]+\lambda[u \ell+\pi+i \cdot p b-x-p y]
$$

where $\lambda$ is the costate variable associated with the accumulation equation (1b). The first order optimality condition with respect to the decision variables $x, y$, and $\ell$, are respectively

$$
\begin{aligned}
& U_{y} V_{x}=\lambda \\
& U_{v} V_{y}=p \lambda \\
& U_{\ell}=-w \lambda
\end{aligned}
$$

In addition, the costate variable $\lambda$ evolves according to

$$
\dot{\lambda}=\left(\delta-i^{\bullet}\right) \lambda
$$

It is well known (and can be seen from (4d)) that as long as $\delta$ and $i^{*}$ are both assumed to be constant, the ultimate attainment of a steady state is possible if and only if $\delta-i^{*}$. Henceforth we assume this to be the case. It then follows from (4d) that $\dot{\lambda}=0$, for all $t$, so that $\lambda$ is always at its long-run equilibrium value $\lambda=\bar{\lambda}$.

Finally, there is the transversality condition

$$
\lim _{t \rightarrow \infty} \bar{\lambda} b e^{-i^{*} t}=0
$$


This ensures that in the presence of perfect capital markets, consumers cannot borrow indefinitely to repay past debt.

The representative firm produces domestic cutput $z$ by means of a production function with capital $k$ and labor as inputs. This function is assumed to have the usual neoclassical properties of positive, but diminishing, marginal products and constant returns to scale; i.e.,

$$
\begin{aligned}
& z=f(k, \ell) \\
& \quad f_{k}>0, f_{l}>0 \\
& f_{k k}<0, f_{l l}<0, f_{k k} f_{l \ell}-f_{k \ell}^{2}=0
\end{aligned}
$$

Profit net of investment expenditure at time $t$ say, is defined to be

$$
\pi(t)=f(k, \ell)-w \ell-C(I)
$$

where

$l=$ rate of investment.

The function $C(I)$ represents the installation costs associated with the purchase of $I$ units of new capital. It is assumed to be an increasing, convex function of $I ; C^{\prime}>0, C^{\prime \prime}>0$. In addition, we assume

$$
C(0)=0, \quad C^{\prime}(0)=1
$$

so that the total cost of zero investment is zero, and the marginal cost of the initial installation is unity. This formulation of the installation function follows the original specification of adjustment costs introduced by Lucas (1968), Gould (1968) and Treadway (1969). ${ }^{3}$ More recent work by Hayashi (1982) and Abel and Blanchard (1983) postulates an installation function which depends upon $k$, as well as $I$. This modification makes little difference to our analysis and for siz. icity we retain the simpler specification.

Thus the frm's optimization problem is to

$$
\text { Maximize } \int_{0}^{\infty} \pi(t) e^{-i^{*} t} d t=\int_{0}^{\infty}[f(k, \ell)-w \ell-C(I)] e^{-i^{*} t} d t
$$

subject to 


$$
\dot{k}=I
$$

and the initial condition

$$
k(0)=k_{0}
$$

Two points should be noted about the formulation of the firm's problem. First, equation (7b) abstracts from depreciation. This simplifies the dynamics considerably, without much loss of generality. Second, for expositional simplicity, (7a) assumes that the firm finances investment through retained earnings. This assumption is unimportant, since as is well known, in a model such as this, which abstracts from taxation, all forms of financing yield the same optimality conditions.

The current-value Hamiltonian for the firm maximization problem is

$$
f(k, \ell)-w \ell-C(I)+q \ell
$$

where $q$ is the costate variable associated with (7b). The relevant optimality conditions for firms. with respect to $\ell$ and $I$ are

$$
\begin{gathered}
f_{\ell}(k, \ell)=w \\
C^{\prime}(I)=q
\end{gathered}
$$

while $q$ evolves according to

$$
\dot{q}=i^{*} q-f_{k}
$$

In addition there is the accumulation equation ( $7 b)$, the initial condition ( $7 c)$, as well as the transversality condition

$$
\lim _{t \rightarrow \infty} q k e^{-i^{*} t}=0
$$


The macroeconomic equilibrium we consider is defined to be one where the planned demand and supply functions derived from the optimizations, consistent with the accumulation equations, clear all markets at all points of time. By combining the optimality conditions for households (4a) - (4e), and for firms (8a) - (8d), together with the accumulation equations (1b), (6), (7b), we can write the equilibrium conditions for the economy as follows:

$$
\begin{aligned}
& U_{v}\left(V(x, y), \ell, V_{x}(x, y)=\bar{\lambda}\right. \\
& U_{v}(v(x, y), \ell) V_{v}(x, y)=p \bar{\lambda} \\
& U_{\ell}(V(x, y), \ell)=-f_{\ell}(k, \ell) \bar{\lambda}
\end{aligned}
$$

$$
\dot{q}=i^{*} q-f_{k}(k, \ell)
$$

$$
\dot{k}=I
$$

$$
p \dot{b}=f(k, \ell)+i^{*} p \dot{b}-x-p y-C(I)
$$

The costate variable $\lambda$ remains constant over time at $\bar{\lambda}$ and is determined by the steady state of the economy.

Equations $(9 a)-(9 c)$ are the usual static equilibrium conditions. Pairwise, these equations may be divided to equate the marginal rate of substitution between goods to their relative price and the marginal rate of substitution between leisure and any good to the product wage, where the real wage in terms of the domestic good, equals the marginal physical product of labor. These three equations may be solved for $x, y$, and $\ell$, in terms of $\bar{\lambda}, k$, and $p,{ }^{b}$ 


$$
\begin{aligned}
& x=x(\bar{\lambda}, k ; p) \quad x_{\bar{\lambda}}<0, x_{k}<0 \quad x_{p}>0 \\
& y=y(\bar{\lambda}, k ; p) \quad y_{\bar{\lambda}}<0, y_{k}<0, y_{p}<0 \\
& \ell=\ell(\bar{\lambda}, k ; p) \quad \ell_{\bar{\lambda}}>0, \quad \ell_{k}>0, \quad \ell_{p}>0
\end{aligned}
$$

Intuitively, an increase in the marginal utility of consumption (of the domestic good), $\bar{\lambda}$, shifts the consumption-leisure tradeof against the consumption of both goods and in favor of labor. A rise in the capital stock, by raising the real wage zate, does the same. Given the marginal utility of consumption $\vec{\lambda}$, an increase in the relative price of the imported good $p$ leads to a substitution away from the imported good in favor of the domestic. This stimulates domestic production, which, with capital fixed in the short run, leads to an increase in employment. However, this describes only the partial effect of a short-run change in $p$. In addition, it generates a jump in $\vec{\lambda}_{z}$ thereby inducing further responses. The complete short-run responses consist of a combination of these two effects and these will be discussed in Section 5 below.

The partial derivatives summarized in (10a) - (10c) depend critically upon certain aspects of our specification. For example, the parallel responses of the two goods and leisure to changes in $q$ and $k$ refect the assumption of complementarity in (2c). More importantly, it is evident from (9a), (9b) that the dependence of $\boldsymbol{x}$ and $y$ on capital, and therefore their time dependence, occurs because of the assumptions: (i) employment is variable, (ii) $U_{v} \neq 0$. If instead, employment is fixed or $U_{v e}=0$, i.e., goods and labor enter the utility function in an additively separable manner, then $x$ and $y$ would be independent of $k$. In that case, they would depend upon $\vec{\lambda}$ and $p$ and would remain at their steady state levels at all times. By contrast, under our assumptions, the gradual accumulation of capital generates serial correlation in consumptions, despite the existence of perfect capital markets.

Equation (9d) equates the net marginal cost of capital to the shadow price of investment $q$. This relationship may be solved to yield 


$$
I=I(7) \quad I^{\prime}>0
$$

which is essentially a Tobin $q$ theory of investment ${ }^{6}$

The final three equations describe the dynamics. Substituting (10c) and (11) into (9c) and (9f), we obtain a pair of autonomous differential equations in $k$ and $q$. These constitute the core of the dynamics. Finally, equation $(9 g)$ equates the economy's current account surplus to the accumulation of foreign assets. This equation may be reduced to an autonomous differential equation in $b$, after substituting the solutions for $q$ and $k$ (see next section).

\section{EQUILIBRIUM DYNAMICS}

Consider first equations (9e) and (9f), which upon substitution of (10c) and (11) may be writien as

$$
\begin{gathered}
\dot{k}=I(q) \\
\dot{q}=i^{*} q-f_{k}(k, \ell(\bar{\lambda}, k ; p))
\end{gathered}
$$

Linearizing this pair of equations, yields

$$
\left(\begin{array}{l}
\dot{k} \\
\dot{q}
\end{array}\right)=\left(\begin{array}{cc}
0 & I_{\imath} \\
-\left[f_{k k}+f_{k \ell} \frac{\partial \ell}{\partial k}\right] & i^{*}
\end{array}\right)=\left(\begin{array}{cc}
k & -\tilde{k} \\
q & -\tilde{q}
\end{array}\right)
$$

where $\tilde{k}, \bar{q}$ denote the steady-state values of $k$ and $q$. The determinant of the matrix of coefficients in $(12)$ is

$$
D \equiv I_{l}\left[f_{k k}+f_{k \ell} \frac{\partial \ell}{\partial k}\right\}
$$

which can be shown to be negative. The eigenvalues are say $\mu_{1}<0, \mu_{2}>0$, so that the long-run equilibrium is a saddlepoint. It is clear that while the capital stock always evolves gradually, the shadow price of capital, $q$, may jump instantaneously in response to new information.

Starting from an initial capital stock $k_{0}$, the stable dynamic time paths followed by $k$ and $q$ are 


$$
\begin{aligned}
& k=\tilde{k}+\left(k_{0}-\tilde{k}\right) e^{u_{1} \ell} \\
& q=\tilde{q}+\frac{\mu_{1}}{I_{q}}\left(k_{0}-\tilde{k}\right) e^{\mu_{1} t}
\end{aligned}
$$

To determine the dynamics of the current account, consider $(9 \mathrm{~g})$,

$$
p \dot{b}=f[k, \ell(\bar{\lambda}, k)]-x(\bar{\lambda}, k)-p y(\bar{\lambda}, k)-C[I(q)]+i^{*} p b .
$$

Linearizing this equation around steady state yields

$$
\dot{p} \dot{b}=\left(f_{k}+f_{\ell} \ell_{k}-x_{\dot{k}}-p y_{k}\right)(k-\tilde{k})-I_{q}(q-\tilde{q})+i^{*} p(b-\tilde{b})
$$

where we are using the fact that $C^{\prime}=1$ at steady state, when $I=0$. But from (13a) and (13b),

$$
q-\tilde{q}=\frac{\mu_{1}}{I_{q}}(k-\tilde{k})
$$

so that

$$
p \dot{b}=\left(f_{k}+\int_{\ell} \ell_{k}-x_{k}-p y_{k}-\mu_{1}\right)(k-\tilde{k})+i^{*} p(b-\tilde{b})
$$

Defining

$$
\Omega \equiv f_{k}+f_{\ell} \ell_{k}-z_{k}-p y_{k}-\mu_{1}>0
$$

and substituting the solution for $k-\bar{k}$ from (13a) into (15), we obtain

$$
p(\tilde{b}-i \cdot b)=\Omega\left(k_{3}-\tilde{k}\right) e^{\mu_{1} t}-i \cdot \tilde{b} p
$$

Assuming that the economy starts out with an initial stock of traded bonds $b(0)=b_{0}$, the solution to $\left(15^{\prime}\right)$ is

$$
p b=p \tilde{b}+\frac{\Omega\left(k_{0}-\tilde{k}\right)}{\mu_{1}-i^{*}} e^{\mu_{1} t}+\left(p\left(b_{0}-\tilde{b}\right)-\frac{\Omega}{\mu_{1}-i^{*}}\left(k_{O}-\tilde{k}\right) e^{i^{*} t}\right.
$$

Invoking the intertemporal budget constraint for the economy, (4e), implies 


$$
p b_{0}=p \tilde{b}+\frac{\Omega}{\mu_{i}-i^{*}}\left(k_{0}-\tilde{k}\right)
$$

so that the solution for $b(t)$, consistent with long-run solvency, is

$$
p \dot{b}(t)=p \tilde{b}+\frac{\Omega}{\mu_{1}-i^{*}}\left(k_{0}-k\right) e^{\mu_{1} t}
$$

From equation (4b), we saw that $\lambda$ is always equal to its steady-state value $\bar{\lambda}$. The complete steady state of the economy is summarized by the following set of equations.

Steady-State

$$
\begin{aligned}
& U_{v}\left[V(\tilde{x}, \tilde{y}), \tilde{\ell} \mid V_{x}(\tilde{x}, \tilde{y})=\bar{\lambda}\right. \\
& U_{u}[V(\tilde{x}, \tilde{y}), \tilde{\ell}] V_{y}(\tilde{x}, \tilde{y})=\bar{\lambda} p \\
& U_{\ell}[V(\tilde{x}, \tilde{y}), \tilde{\ell}]=-\bar{\lambda} F_{\ell}(\tilde{k}, \tilde{\ell})
\end{aligned}
$$

$$
f_{k}(\tilde{k}, \tilde{e})=i
$$

$$
\begin{aligned}
& f(\tilde{k}, \tilde{\ell})-\tilde{x}-p \tilde{y}+i^{*} p \tilde{b}=0 \\
& p b_{0}=p \tilde{b}-\frac{\Omega}{i^{2}-\mu_{1}}\left(k_{0}-\tilde{k}\right)
\end{aligned}
$$

determine: $\tilde{x}, \tilde{y}, \tilde{\ell}, \tilde{k}, \tilde{\lambda}, \tilde{q}, \tilde{b}$.

This long-run equilibrium is straightforward, although several aspects merit comment. Note that the steady-state value of $q$ is unity, consistent with the Tobin $q$ theory of investment. The 
steady-state marginal physical product of capital is equated to the foreign interest rate. Equation (18f) asserts that in steady state equilibrium, the balance of payments on current account must be zero; the trade balance must offset net interest earnings on the traded bonds. Equation (18g) describes the equilibrium relationship between the change in the equilibrium stock of capital and the change in the equilibrium net credit of the economy. Specifically,

$$
p d \tilde{b}=-\frac{\Omega}{i^{*}-\mu_{1}} d \tilde{k}
$$

from the definition of $\Omega$ we can show

$$
\frac{\Omega}{i^{*}-\mu_{1}}>1
$$

so that any unit increase in the stock of capital leads to a greater decrease in the net credit position of the domestic economy (as measured in terms of domestic currency). Note further, that the steady state depends upon the initial conditions $k_{0}$ and $b_{0}$. This has important consequences for the effects of temporary shocks in the terms of trade, as we will discuss below.

The rest of the model is also summarized below.

Short-Run:

$$
\begin{gathered}
U_{y}[V(x, y), \ell] V_{x}(x, y)=\bar{\lambda} \\
U_{u}[V(x, y), \ell] V_{y}(x, y)=\vec{\lambda} p \\
U_{\ell}[V(x, y), \ell]=-\bar{\lambda} f_{\ell}(k, \ell) \\
C^{\prime}(I)=q
\end{gathered}
$$

determine: $x, y, \ell<I$ in terms of $\bar{\lambda}, x$, and $g$.

Dynamics: 


$$
\begin{gathered}
k=\tilde{k}+\left(k_{0}-\tilde{k}\right) e^{\mu_{1} t} \\
q=\tilde{q}+\frac{\mu_{1}}{I_{\nabla}}\left(k_{0}-\tilde{k}\right) e^{\mu_{1} t} \\
p^{b}=p \tilde{b}-\frac{\Omega}{i^{*}-\mu_{i}}\left(k_{0}-\tilde{k}\right) e^{\mu_{1} t}
\end{gathered}
$$

determine: time paths for $k, q, b$.

The short run has been discussed in Section 2. Equations (19) highlight the fact that it depends directly upon the steady state through $\bar{\lambda}$. Finally, the stable adjustment paths are described by the linear relations in (20). From these equations it is seen that the accumulation of capital $(\dot{k}>0)$ is accompanied by a current account deficit $(p \dot{b}<-1<0)$.

\section{LONG-RUN RESPONSE TO TERMS OF TRADE SHOCK}

Since the analysis is based on the assumption of perfect foresight, the transitional adjustment is forward looking and is therefore determined in part by the expectations of the long-run steady state. It is therefore convenient to begin with a consideration of the long-run equilibrium effects of a deterioration in the terms of trade.

Consider the equilibrium relationships $(18 \mathrm{a})-(18 \mathrm{~g})$. Since the world interest rate ${ }^{*}$ is assumed to remain fixed, the marginal product condition (18e) implies that the long-run capital-1abor ratio $(k ; k)$ is a constant, independent of $p$. Capital and labor therefore change in the same proportions, so that the marginal physical product of labor and hence the real wage, also remain constant. It is clear from these equilibrium relationships that any change resulting from a deterioration in the terms of trade $p$ can be broken down into a substitution effect (the change originating in (18b) and $(18 \mathrm{c})$ ) and an income effect (due to changes in (18f) and (18g)). In the case of $\tilde{x}, \tilde{y}, \bar{\ell}, \tilde{k}$, and $\bar{\lambda}$, this latter effect is inversely proportional to $\left(\tilde{y}-i^{*} b_{0}\right)$. On the one hand, any rise in $p$ reduces real income, to the extent that it is spent on the imported good $y$. At the same time, the increase in $p$ raises real interest income earned from abroad (assuming $b_{0}>0$ ). For the sake of being concrete we shall assume that the import good effect dominates $\left(y-i^{*} b_{0}>0\right)$, so that any increase in $p$ lowers tota! real domestic income. 
Table 1 summarizes the qualitative effects of the substitution and income effects on a number of key variables. Turning first to the substitution effects, the following intuitive explanations for these results may be given. An increase in the relative price $p$ causes a substitution away from the imported good, in favor of the domestic good. Given the assumption that goods are complementary in utility $\left(U_{x y}>0\right)$, these two adjustments both lead to a reduction in the marginal utility of consumption $\dot{\lambda}$. With the real wage being constant (independent of $p$ ), this raises $U_{l}$ (i.e, makes it less negative), which in tum implies that equilibrium employment falls. Capital falls in the same proportion, as does output. From $(18 \mathrm{~g}$ ) it then follows that the negative substitution effect in capital gives rise to a positive substitution effect in the stock of trade bonds.

To consider the steady-state trade balance, we may rewrite (18f) as

$$
\tilde{T}=f(\tilde{k}, \tilde{\ell})-\tilde{x}-p \tilde{y}=-i \cdot p \tilde{b}
$$

which together with $(18 \mathrm{~g})$ implies

$$
\tilde{T}=-i^{*} b_{O P}-\frac{\Omega i^{*}}{i^{*}-\mu_{1}}\left(k_{0}-\tilde{k}\right)
$$

so that the negative substitution effect implies a corresponding negative substitution effect for the equilibrium balance of trade.

We turn now to the income effects. With $y-i^{*} b_{0}>0$, an increase in $p$ lowers real income, which with $x$ and $y$ being normal goods, reduces their consumption. The lower income raises the marginal utility of consumption, $\bar{\lambda}$, which lowers $U_{\ell}$ (i.e., makes it more negative). Employment therefore rises, as does capital and output. From (21), the trade balance is subject to two sources of income effects. The first operates through the equilibrium stock of capital and is positive the second is in the decrease in $p b_{0}$ and is negative. On the other hand, from (18g) it is seen that although the stock of bonds is also subject to two sources of income effects, to the first order, the positive income effect in capital dominates, and gives rise to a negative effect in $b$.

From Table 1 it is apparent that in most cases the substitution and income effects go in opposite ways. One exception is the obvious one; the imported good $y$, in which both effects act to reduce its consumption. It is also likely, but not necessary, that the negative component of the income effect in the balance of trade is the dominant one, in which case, the long-run equilibrium 
trade balarce deteriorates unambiguously as wel. In all other cases, the ultimate long-run response depends upon whether the substitution effect or the income effect dominates. This is particularly important with respect to capital, since as we will discuss in the next section, the long-run response of capital has an important bearing on the short-run transitional dynamics of the system.

\section{TRANSITIONAL DYNAMICS IN RESPONSE TO TERMS OF TRADE SHOCK}

We turn now to a consideration of the transitional dynamics following a worsening of the economy's terms of trade (i.e, an increase in the relative price $p$ ). As noted previously, the dynamics of $q$ and $k$ are described by a saddlepcint in $k$ - $q$ space. The stable arm $X X$ is given by

$$
q=1+\frac{\mu_{1}}{I_{q}}(k-\tilde{k})
$$

and is negatively sloped; the unstable arm $Y Y$ is described by

$$
q=1+\frac{\mu_{2}}{I_{q}}(k-\tilde{k})
$$

and is positive sloped. The phase diagram is illustrated in Fig. 1.

As long as no future shock is anticipated, the system must lie on the stable locus $X X$. The initial jump in $q(0)$, following an unanticipated permanent increase in $p$ is

$$
\frac{d q(0)}{d p}=-\frac{\mu_{1}}{I_{\tau}} \frac{d \tilde{k}}{d p}
$$

The short-run response of $q$ depends upon the long-run behavior of the capital stock, which as we have seen depends upon whether the income effect or the substitution effect of the terms of trade change dominates. In principle, either outcome is possible, depending upon the nature of the underlying utility function. For example, if the utility function is taken to be additively separable in goods and leisure (rather than weakly separable), then we can show that, with the imposition of the additional rather mild restriction $U_{y}+y U_{y y}>0$, the substitution effect will dominate. However, the complementarity of leisure and consumption which we have been assuming, tends to strengthen the income effect and if this is sufficiently large, it is then possible for this to dominate instead. 
Figures 2 and 3 illustrate the dynamic adjustment paths in response to deterioration in the terms of trade $p$. The former illustrates the case where the contractionary substitution effect of $p$ on the long-run capital stock dominates; the latter deals with the other situation, namely, where the long-run income effect prevails. Each figure in turn consists of two parts. Part A describes the dynamics of $q$ and $k$, while part $B$ illustrates the time path of the stock of traded bonds. Various types of disturbances are illustrated and shall be discussed in turn.

We shall focus our remarks primarily on the case illustrated in Fig. 2, the other case being essentially analogous. Suppose that the economy is initially in steady state equilibrium at the point $P$ on the stable arm $X X$ and that an unanticipated permanent increase in the terms of trade $p$ occurs. With the long-run substitution effect dominant, the new steady state is at the point $Q$. having a lower equilibrium capital stock $\tilde{k}$, with an unchanged equilibrium shadow price of capital $q=1$.

In the short run, $q$ drops from $P$ to $A$ on the new stable locus $X^{\prime} X^{\prime}$. From (11) it is seen that the decrease in $q$ has an immediate contractionary effect on investment, so that the capital stock immediately begins to decumulate.

The initial effects of change in the terms of trade on consumption and employment are given by:

$$
\begin{aligned}
& \frac{d x(0)}{d p}=\frac{\partial x(0)}{\partial p}+\frac{\partial x}{\partial \bar{\lambda}} \frac{\partial \vec{\lambda}}{\partial p} \\
& \frac{d y(0)}{d p}=\frac{\partial y(0)}{\partial p}+\frac{\partial y}{\partial \bar{\lambda}} \frac{\partial \bar{\lambda}}{\partial p} \\
& \frac{d \ell(0)}{d p}=\frac{\partial \ell(0)}{\partial p}+\frac{\partial \ell}{\partial \bar{\lambda}} \frac{\partial \bar{\lambda}}{\partial p}
\end{aligned}
$$

each of which can be seen to comptise two effects. The first represents the direct effects associated with the change. These come into operation when the shock actually occurs. As discussed in connection with equations $(10 \mathrm{a})-(10 \mathrm{c})$, the direct effect of an increase in the relative price of the imported good is to shift demand away from that good, towards the domestic good, thereby stimulating employment. But any terms of trade shock also affects the steady-state marginal utility 
A. thereby exercising a second channel of infuence on short-run consumption and employment. This too comes into effect only when the shock occurs and the current steady atate changes. Thus while in our model $\lambda$ is a jump variable and may appear to be analogous to an information variable, it is not forward looking. Instead, it reacts to current changes as they occur, and this has important implications for announcement effects to be discussed below. ${ }^{7}$

Qualitatively, these second effects depend upon how $p$ affects $\bar{\lambda}$, and as discussed in Section 4, this too has a substitution and an income effect. In the special case where the utility function is additively separable in consumption and leisure, so that $U_{y \ell}=0$, we have

$$
\operatorname{sgn}\left(\frac{d \bar{d}}{d p}\right)=\operatorname{sgn}\left(\frac{d \tilde{k}}{d p}\right)
$$

In this case, the substitution and income effects of $\bar{\lambda}$ will be qualitatively the same as the corresponding long-run effects for capital. Hence, in the case being illustrated in Fig. 2, where the long-run substitution effect causes $k$ to fall, $\bar{\lambda}$ falls as well For expositional convenience, we shall consider this to be the case, although it neec not be precisely so with the more general utility function.

Thus under the present assumption, the second effect of the increase in the relative price $p$ is to lower the constant marginal utility of the domestic good $\bar{\lambda}$. This raises the consumption of that good, which given the complementarity of goods and leisure, raises the consumption of the imported good and reduces work (employment). It is immediately apparent that both thechannels act to increase the consumption of the domestic good, while the effects on the import good and labor are offsetting. However, in the latter case it can be shown that the second effect dominates, causing short-run employment to fall as well.

Taking the differential of ( $9 e)$, we find

$$
d \dot{q}(0)=i d q(0)-f_{k \ell} d \ell(0)
$$

In fact, the initial fall in employment is sufficiently large to reduce the marginal physical product of capital below $i^{*}$, so that following its initial decline, $q$ immediately begins to rise. The economy thus begins to move continuously along the locus $A Q$ towards the new steady state, $Q$. 
The crucial role played by the endogeneity of employment in these adjustments can be seen by considering the steady state relationships (18). Under the assumption of fixed employment, the optimality condition (18c) is no longer applicable, while the marginal product of capital condition (IBe) now implies that the steady-state stock of capital $\vec{k}$, rather than the capital-labor ratio, is determined solely by the foreign interest rate $i^{*}$ and is therefore independent of the terms of trade p. Since the short-run dynamics are driven by changes in the steady-state stock of capital $\tilde{k}_{x}$ it Collows from (20a), (20b) that in the absence of such changes both $k$ and $q$ remain constant over time. Output therefore also remains fixed. All that happens is that the consumptions of the two goods adjust instantaneously to the change in the relative price.

One reason why the dynamics does not degenerate in either the Matsuyama (1987) model or the Brock (forthcoming) model, even though employment is fixed, is because of, in both cases, the inclusion of a third factor in the production function. In the Matsuyama model it is imported ofli in the Brock model it is land. In either case, the macroeconomic shock causes a shift in this third factor of production, which in turn requires a corresponding change in the steady-state stock of capital, in order for the equilibrium marginal product of capital condition to be maintained. In addition, although labor is fixed in the aggregate in the Brock model, it is mobile across sectors. and this fact also permits changes in the steady-state capital stock. Given adjustment costs, these changes occur over time.

Part $B$ illustrates the relationship between $b$ and $k$, which combining $(20 \mathrm{a})$ and $(20 \mathrm{c})$ is

$$
p(b-\tilde{b})=-\frac{n}{i^{*}-\mu_{1}}(k-\tilde{k})
$$

This too is negatively sloped and is denoted by $Z Z$. Since neither $b$ nor $k$ are jump variables, an increase in $p$ leads to a counterclockwise rotation of the $Z Z$ line around the point $L$. The movement along $A$ and $Q$ in Part $A$ is translated to a movement along $L M$ on $Z^{\prime} Z^{\prime}$ in Part $B$. From this figure it is immediately seen that a worsening of the terms of trade leads to an immediate accumulation of foreign bonds. With the level of net indebtedness $b$ being given instantaneously, this is brought about by an improvement in the trade balance, which in turn is a consequence of the fact that the initial reduction in investment more than outweighs the initial reduction in output stemming from the reduced employment, together with any increase in consumption. 
Over time, this intial improvement in the trade balance is reversed. This occurs through decreasing employment and capital decumulation, leading to further reductions in output, together with increasing consumption.

Consider now a temporary deterioration in the terms of trade. Specifically, suppose that at time $0, p$ increases, but is expected to be restored to its original level at time $T$. The transitional adjustment is now as follows. As soon as the increase in poccurs, the stable arm $X X$ will drop instantaneously (and temporarily) to $X^{\prime} X^{\prime}$, while the shadow price $q$ falls to the point $B$; which lies above $X^{\prime} X^{\prime}$. At the same time, the marginal utility of consumption $\vec{\lambda}$ will increase by precisely the same (constant) amount so if the shock were permanent. Initial consumption and employment therefore respond by precisely the same amounts as indicated in (23a) - (23c). On the other hand, since the fall in the shadow price $g(0)$ is only to the point $B$, the fall in initial investment is moderated. As a tesult of the initial fall in $q$, capital begins to decumulate and $q$ begins to rise, for analogous reasons to those noted in connection with the permanent shock. Moreover, the decumulation of capital is accompanied by an accumulation of traded bonds. Immediately following the initial jump, $q$ and $k$ follow the path $B C$ in Fig. 2.A, while $k$ and $b$ follow the corresponding path $L H$ in Fig. 2.B. At time $T$, when the relative price $p$ is restored to its original level, the stock of capital and traded bonds will have reached a point such as $H$ in Fig. 2.B. The accumulated stocks of these assets, denoted by $k_{T}$ and $b_{T}$ respectively, will now serve as initial conditions for the dynamics beyond time $T$ when $p$ reverts permanently to its original level. As noted in Section 3 , they will therefore in part determine the new steady state equilibrium. With no new information being received at time $T$ (since the temporary nature of the shock was announced at the outset), and no further jumps, the stable locus relevant for subsequent adjustments in $q$ and $k$ beyond time $T$ is the locus $X^{\prime \prime} X^{\prime \prime}$, parallel to $X X$ which passes through the point $k=k_{T}$. Likewise, the relevant locus linking the accumulation of capital and traded bonds is now $Z^{\prime \prime} Z^{\prime \prime}$. Note that since the relative price has now been restored to its original level, this is parallel to $Z Z$, the original curve.

After time $T, q$ and $k$ follow the stable locus $C R$ in Fig. 2.A to the new steady state equilibrium at $R$, while correspondingly $k$ and $b$ follow the locus $H N$ in Fig. $2 . B$ to the new equilibrium point $N$. One can establish formally that $X^{\prime \prime} X^{\prime \prime}$ lies below the original stable locus $X X$, while $Z^{\prime \prime} Z^{\prime \prime}$ lies 
above $Z Z$, as these curves have been drawn. In the new steady state, the shadow price $q$ reverts to 1 , but with a lower stock of capital and a higher stock of traded bonds than originally. The striking feature of the adjustment is that the temporary deterioration of the terms of trade leads to a permanent reduction in the stock of capital, accompanied by a higher stock of traded bonds. This is because during the transitional adjustment period, during which the higher terms of trade is in effect, the accumulation of capital and bonds will infuence subsequent initial conditions, which in turn will affect the subsequent steady state.

As the figures are drawn, $C$ lies below $R$ and $H$ lies below $N$, respectively. The complete adjustment paths $B C R$ and $L H N$ are therefore monotonic. We are unable to rule out the possibility of $C$ lying above $R$ and $H$ lying above $N$, in which case, the accumulation of capital and accumulation of bonds would be reversed at some point during the transition. In any event, the temporary increase in the terms of trade generates an initial current account surplus, which continues as long as capital is being decumulated.

One further point, in this case of a temporary shock (as in Obstfeld (1983)), the anticipation of the future change in the term of trade (when the latter is expected to revert to its original level), will lead to a discontinuity in consumption, even if the utility function is additively separable in goods and leisure. This is due to an "intertemporal price speculation effect.". That ia, an anticipated future improvement in the terms of trade will make the relevant rate of interest for consumption fall at the moment when the improvement is expected to occur and hence induce agents to postpone consumption. In our model, the interest rate also have an effect on $q$. The interest rate relevant for discounting future marginal product of capital is $i^{*}+\underset{p}{\dot{p}}$ (from $(8 c)$ ). If this is expected to fall, then the jump in $q$ is moderated.

As a third disturbance, we briefly consider a future permanent increase in $p$ which is announced at time 0 , to take effect at time $T$. This is not illustrated in the figure. At the time of the announcement, $q$ drops instantaneously to a point auch as $B$, which lies above $A$ on $X^{\prime} X^{\prime}$. This reduction in $q$ implies a smaller initial decumulation in the capital stock, than when the permanent deterioration occurs instantaneously.

Since neither $\bar{\lambda}$ nor $p$ change immediately, there is no initial response in consumption or employment at the time of the announcement. The marginal physical product of capital remains 
fixed instantaneously. It therefore follows from (9e) that after its initial decline, $q$ immediately continues to fall. Thus following the announcement, both $q$ and $k$ decline, while foreign bonds are accumulated. At time $T$, when the announced increase in the relative price $p$ occurs, the stocks of capital and bonds at that time $k_{T}, b_{T}$ will determine the stable paths $X^{\prime \prime} X^{\prime \prime}$ and $Z^{\prime \prime} Z^{\prime \prime}$ relevant for the subsequent adjustments, beyond time $T$. Note, because of the changed initial conditions at time $T$, from time 0 , these paths will not coincide with $X^{\prime} X^{\prime}, Z^{\prime} Z^{\prime}$, the corresponding paths for unannounced changes. In particular, the locus $X^{\prime \prime} X^{\prime \prime}$ can be shown to lie above $X^{\prime} X^{\prime}$ in Fig. 2.A, implying that the ultimate reduction in the steady state capital stock resulting from an increase in $p$ is less when this shock is announced, than when it is unanticipated.

We conclude by briely referring to Fig. 3 , which illustrates the other case where the steadystate income effect of the increase in $p$ on the long-run capital stock dominates. In this case, as discussed previously, the new steady state is one with a higher stock of capital. The time paths following the disturbances are seen to be mirror images of those we have been discussing Specifically, a permanent increase in the relative price $p$-either anticipated or unanticipatedleads to a steady accumulation of capital, accompanied by a current account deficit, leading to a steady decumulation of traded bonds. A temporary increase in $p$, will now lead to a permanent increase in the stock of capital, accompanied by a permanent reduction in the stock of traded bonds.

\section{CONCLUSIONS}

This paper has analyzed the effects of a deterioration in the terms of trade on a small open economy. The model, based on intertempcral optimization, has emphasized the labor-leisure choice and the role of capital accumulation. Three types of disturbances in the terms of trade have been considered: (i) unanticipated permanent; (ii) unanticipated temporary; (iii) anticipated permanent. There are two main conclusions to be drawn from the analysis. The first is that in all cases the transitional dynamics depends critically upon the long-run response of the capital stock to the deterioration in the terms of trade. This has been shown to consist of a substitution effect, which is negative, together with an income effect, which is positive. Secondly, since the steady state equilibrium depends upon the initial conditions of the economy, a temporary shock, 
by altering these initial conditions for some later date when the shock ceases, leads to a permanent effect on the economy.

In the case where the substitution effect dominates, a permanent deterioration in the terms of trade leads to a long-run reduction in the stock of capital. This in turn gives rise to a short-run reduction in the shadow price of capital, leading to a short-run reduction in investment and a short-run current account surplus, which of course is contrary to the Laursen-Metzler effect. The same applies with respect to a temporary change, although the subsequent effects are mitigated.

If on the other hand, the long-run income effect dominates, the deterioration in the terms of trade leads to a long-run accumulation in the stock of capital. This lead to short-run investment boom, accompanied by a short-run current account deficit. The Laursen-Metzler effect is in existence, although it is driven by investment, rather than savings behavior. 


\section{TABLE 1}

\section{STEADY-STATE EFFECTS OF PERMANENT}

DETERIORATION IN TERMS OF TRADE

$\begin{array}{ll}\text { Substitution } & \text { Income } \\ \text { Elfect } & \text { Effoct }\end{array}$

Consumption of Domestic Good $x$

Consumplion of Imponcd Good y

Enploymen! !

Capilisl-Labor Ratio $k / l$

Capital $k$

Outpus:

Balance of Trade

Siock of Trade Bonds $b$

$\begin{array}{ll}+ & - \\ - & + \\ 0 & 0 \\ - & + \\ - & + \\ + & +\end{array}$




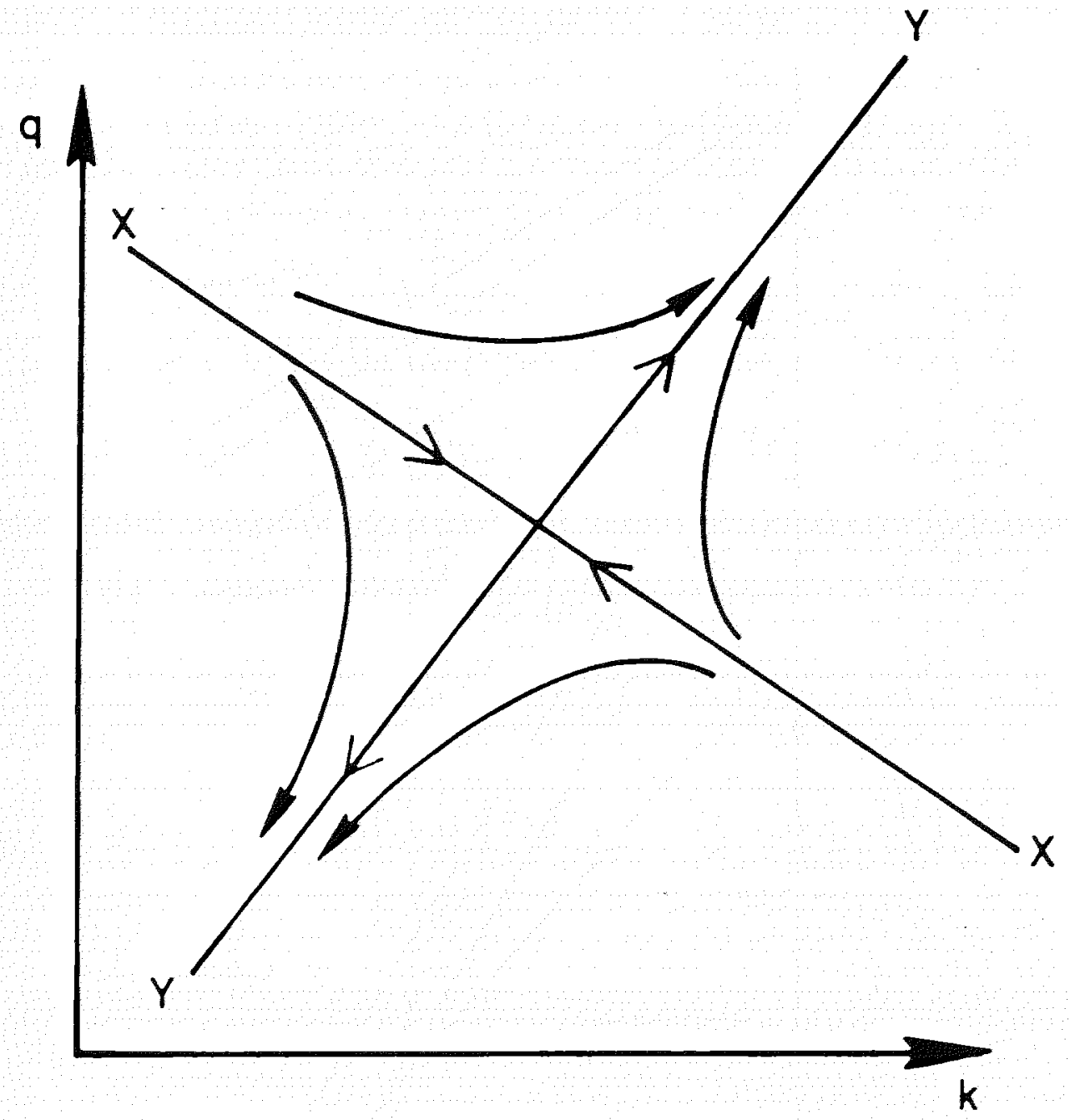

Figure 1

Phase Diagram 


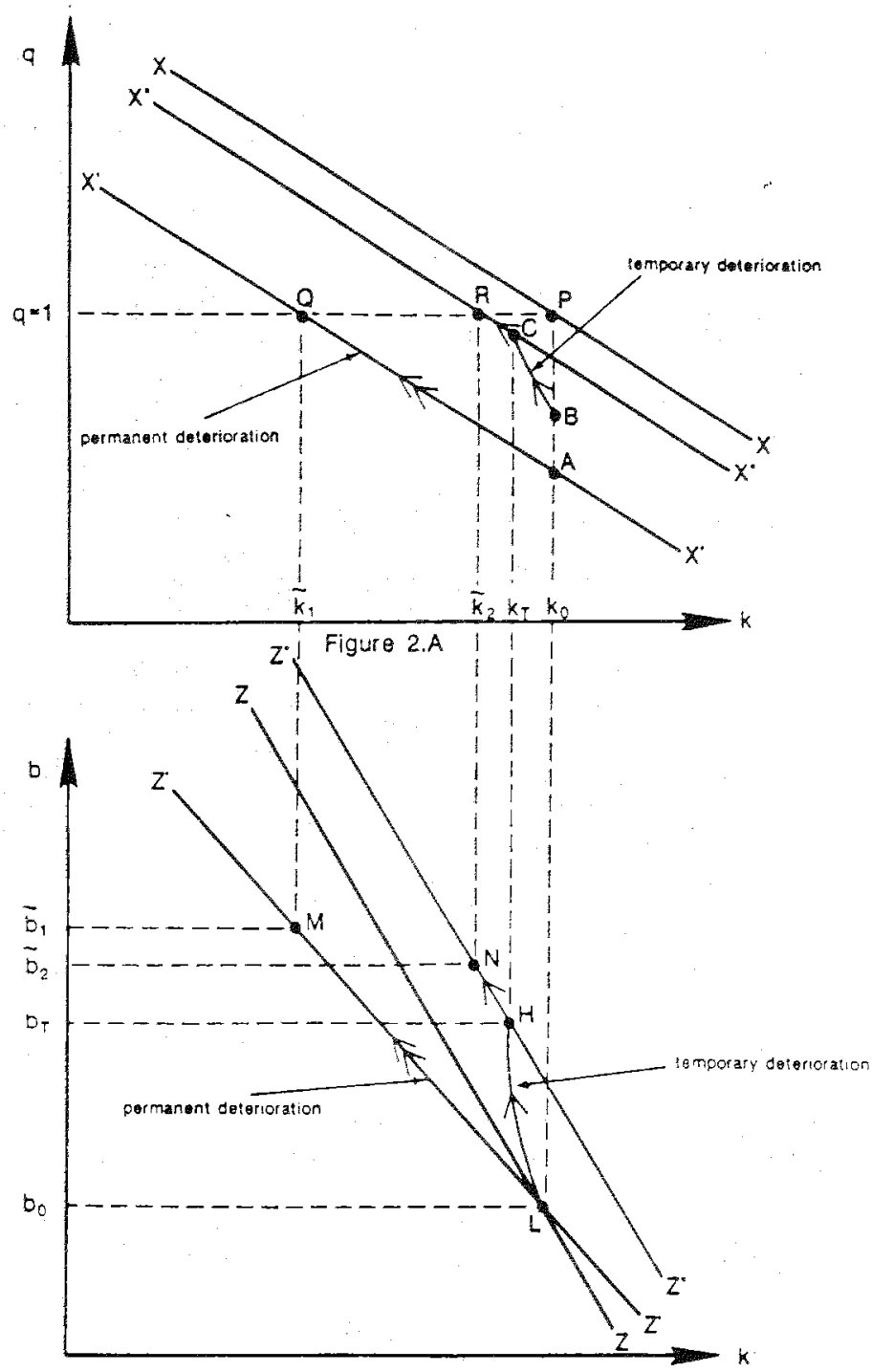

Figure 2.8

Deterioration of Terms of Trade:

Long-Run Substitution Effect Dominant 


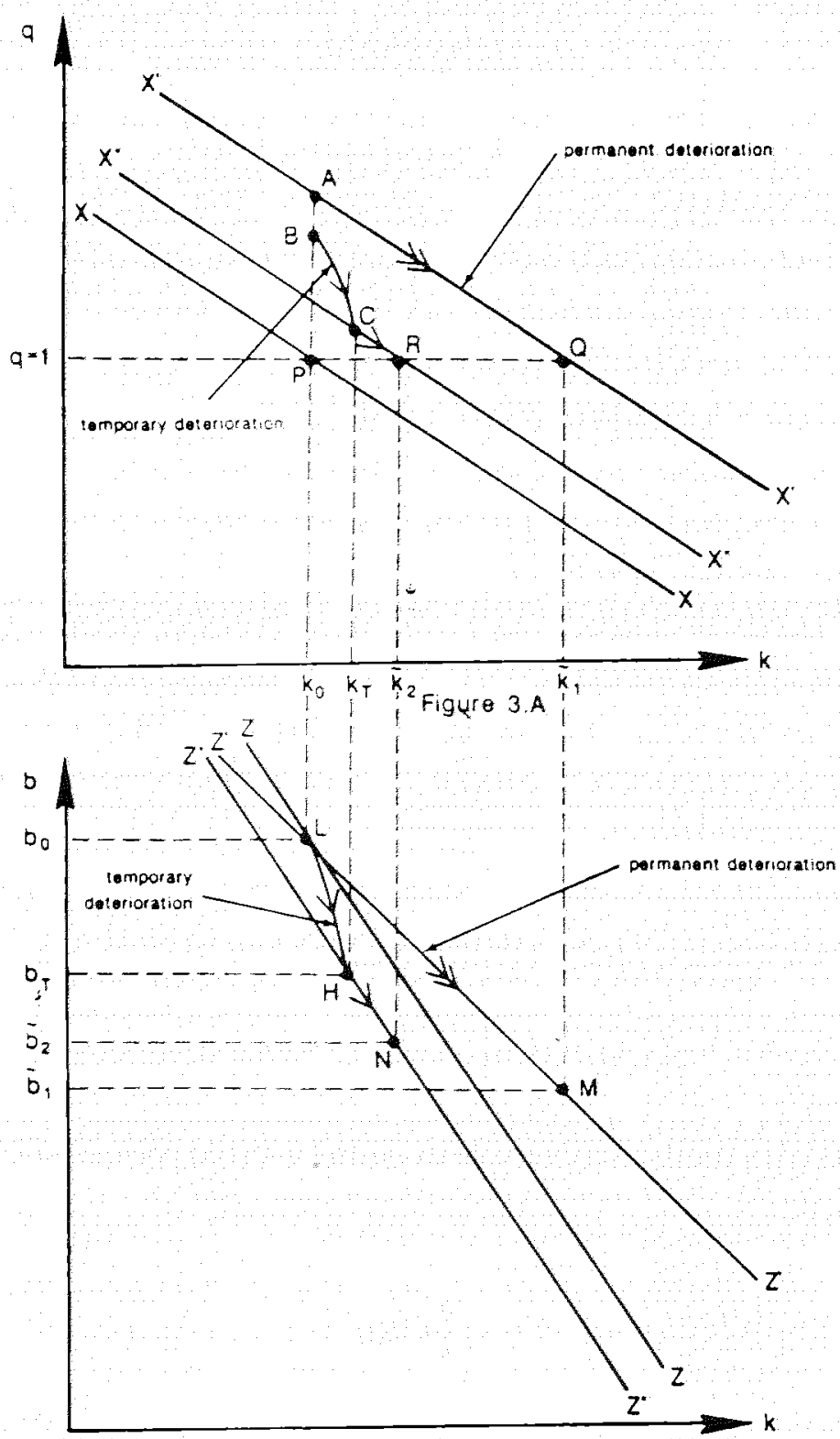

Figure 3.8

Deterioration of Terms of Trade:

Long-Run income Eftect Dominant 


\section{FOOTNOTES}

- We are grateful to the referee for drawing uwe attention to the papers of Philip Brock and K. Matsuyama.

ISpecifically, Obstfeld (1983) shows how a temporary deterioration of the terms of trade leads to a current account deficit for the duration of the adverse movement in the terms of trade. Eventually, the current account moves into surplus, when the terms of trade shock ceases and the economy returns to its initial long-run equilibrium level.

${ }^{2}$ Throughout the paper we shall adopt the following notational convention. Where appropriate, primes shall denote derivatives, subscripts shall denote partial derivatives, and a dot shall denote a derivative with respect to time.

Note that this specification implies that in the case where disinvestment may occur, $I<$ $0, C(I)<0$ for low rates of disinvestment. This may be interpreted as reflecting the revenue obtained as capital is sold off. The possibility that all changes in capital are costly can be incorporated by introducing sufficiently large fixed costs, so that $C(0)>0$. This does not alter our analysis in any substantive way.

${ }^{4}$ For simplicity and without essential loss of generality we shall abstract from a government sector. Its conclusion would be straightforward and would not alter our analysis in any essential way.

${ }^{5}$ The details of these calculations and others are omitted from the paper, but are avalable from the authors.

${ }^{\circ}$ In the case where the installation costs are specified by $C(I / k)$, the investment function (11) is modified to

$$
\frac{I}{k}=I(q)
$$

${ }^{7}$ In other models when $\lambda$ is not a constant it can react to future shocks (as $q$ does in this analysis).

${ }^{8}$ Letting $T$ denote the trade balance, equation $(9 \mathrm{~g})$ can be written as 


$$
\dot{b}=\frac{T}{p}+i \bullet b
$$

From this equation it is clear that the accumulation of foreign bonds resulting from the increase in $p$ must be due to an increase in the trade balance $T$.

${ }^{2}$ The formal derivations of these adjustment paths are svailable from the authors on request. 


\section{REFERENCES}

Abel, A.B. and O.J. Blanchard (1983), "An Intertemporal Model of Saving and Investment," Econometrica 51,673-692.

Bean, C.R. (1986), "The Terms of Trade, Labor Supply, and the Current Account" Economic Journal Supplement $96,38-46$.

Brock, P.L., "Investment, the Current Account, and the Relative Price on Non-Traded Goods in a Small Open Economy, Journal of International Economics (fortheoming).

Gould, J.P. (1968), "Adjustment Costs in the Theory of Investment of the Firm," Revicw of Economic Studies $35,47-56$.

Harberger, A.C. (1950), "Currency Depreciation, Income and the Balance of Trade," Journal of Political Economy $58,47-60$.

Ifayashi, F. (1982), "Tobin's $q$, Rational Expeciations, and Optimal Investment Rule," Economet. rica $50,213-224$.

Laursen, S. and L. M. Metzler (1950), "Elexible Exchange Rates and the Theory of Employment," Review of Economics and Statistice 32, 231-299.

Lucas, R.E. (1967), "Adjustment Costs and the Theory of Supply," Journol of Political Economy $75,321-334$.

Maysuyama, K. (1987), "Current Account Dynamics in a Finite Horizon Model," Journal of International Economics 23, 299-313.

Satsuyama, K. (1988), "Terms of Trade, Factor Intensities and the Current Account in a LifeCycle Model," Review of Economic Studies 55, 247-262.

Obstfeld, M. (1982), "Aggregate Spending and the Terms of Trade: is There a Laursen-Metzlet Effect?" Quarterly Journal of Economics 97, 251-270.

Obstfeld, M. (1983), "Intertemporal Price Speculations and the Optimal Current-Account Deficit," Journal of International Money and Finance 2, 135-145.

Persson, T. and L.E.O. Syensson (1985), "Current Account Dynamics and the TErms of Trade: Harberger-Laursen-Metzler Two Generations Later," Journal of Political Economy 93, 43-65. Svensson, L.E.O. and A. Razin (1983), "The Terms of Trade and the Current Account: The 
Harberger-Laursen-Metzler Effect," Journal of Political Economy 91, 97-125.

Treadway, A. (1969), "On Rational Entrepreneurial Behavior and the Demand for Investment," Review of Economic Studies 36, 227-240. 